\title{
Environmental/Economic Power Dispatch Problem /renewable energy Using firefly algorithm
}

\author{
Mimoun Younes, \\ Faculty of Technology \\ Djillali Liabes University
}

Sidi Bel Abbes, 22000, Algeria

\author{
Riad Lakhdar Kherfene, Fouad Khodja \\ Faculty of Technology \\ Djillali Liabes University \\ Sidi Bel Abbes, 22000, Algeria
}

Received: January 27, 2021. Revised: March 15, 2021. Accepted: March 17, 2021. Published: March 23, 2021.

\begin{abstract}
Exploitation and development of renewable energy such as solar and wind energy is a very important alternative to reduce gas emissions, reduce the bill for power generation. This paper examines the implications of renewable energy deployment in power generation with the classical energy system, managed by an intelligent method, to minimize the cost of production of electric energy and also reduce the emission of gases. Simulation results on the 10 units power system prove the efficiency of this method thus confirming its capacity to solve the environmental/economic power dispatch problem with the renewable energy.
\end{abstract}

Keywords- Economic Power Dispatch (EPD); renewable energy; environmental, an intelligent method

\section{INTRODUCTION}

Electricity is regarded as the invention that changed the world; some centuries ago the world was in total darkness.Currently electricity is virtually present in all our activities.With the advanced technology on the one hand, and population growth on the other hand, these two factors have made the world a voracious and ravenous appetite for electricity. Most predictions to ensure the growth of energy consumption in developed countries in the compositions to about $1 \%$ per year, but for developing countries, consumption now exceeds $5 \%$ per year [1]. With the increasing negative effects of fossil fuel combustion on the environment in addition to limited stock of fossil fuel have forced many countries to inquire into and change to environmentally friendly alternatives that are renewable to sustain the increasing energy demand. Energy policy plays a vital role to mitigate the impacts of global warming and crisis of energy availability [2].The problem which has received much attention. It is of current interest of many utilities and it has been marked as one of the most operational needs. In traditional economic dispatch, the operating cost is reduced by the suitable attribution of the quantity of power to be produced by different generating units. However the optimal production cost can not be the best in terms of the environmental criteria. Recently many countries throughout the world have concentrated on the reduction of the quantity of pollutants from fossil fuel to the production of electrical energy of each unit. The gaseous pollutants emitted by the power stations cause harmful effects with the human beings and the environment like the sulphur dioxide ( $\mathrm{SO} 2)$, nitrogen oxide (NOx) and the carbon dioxide (CO2), etc. Thus, the optimization of production cost should not be the only objective but the reduction of emission must also be taken into account. Considering the difference in homogeneity of the two equations, the equation of the cost of fuel given in $\$ / \mathrm{hr}$, and the equation of emission of gases to the production of electrical energy given in $\mathrm{Kg} / \mathrm{hr}$. Algeria has substantial resources and inexhaustible renewable energy ie solar radiation exceptional covers an area of 2,381,745 km2, with over 3000 hours of sunshine per year and the existence of significant wind energy potential. Moreover, these energies are clean, renewable and are used where they are and their decentralized nature is well suited to the state of scattered areas of low population density. Consequently, they can contribute to environmental protection, reduce the emission of greenhouse gases, particularly a successful $\mathrm{CO} 2$ reduction, and to combat global warming, be considered as a future alternative to conventional energy, increased energy independence and preservation of raw materials. Our work revolves around two main axes: the injection of the maximum power produced from renewable energy sources in the Algerian network. Optimal management of power produced by conventional power plants by an improved firefly algorithm ( FFA). Simulation results on the 10 units power system prove the efficiency of this method thus confirming its capacity to solve the environmental/economic power dispatch problem with the renewable energy.

\section{PROBLEM FORMULATION AND OPTIMIZATION WITH THE SOLAR ENERGY AND WIND ENERGY}

\section{1) Solar Energy}

The maximum power provided by a solar panel is given by the following characteristic [3]:

$$
P_{s}=P_{1} \cdot E_{c} \cdot\left[1+P_{2} \cdot\left(T_{j}-T_{j r e f}\right)\right]
$$

$\mathrm{Ec}$ is solar radiation, $\mathrm{T}_{\text {jref }}$ is the reference temperature of the panels at $25^{\circ} \mathrm{C}, \mathrm{T}_{\mathrm{j}}$ is the cells junction temperature $\left({ }^{\circ} \mathrm{C}\right)$, P1represent the characteristic dispersion of the panels and the value for one panel is included enters 0.095 to 0.105 and the parameter $\mathrm{P}_{2}=0.47 \% / \mathrm{C}^{\circ}$; is the drift in panels temperature [3].

The addition of one parameter $\mathrm{P}_{3}$ to the characteristic, gives more satisfactory results: 


$$
P_{s}=P_{1} \cdot\left[1+P_{2} \cdot\left(T_{j}-T_{j r e f}\right)\right] \cdot\left(P_{3}+E_{c}\right)
$$

This simplified model makes it possible to determine the maximum power provided by a group of panels for solar radiation and panel temperature given, with only three constant parameters $\mathrm{P}_{1}, \mathrm{P}_{2}$ and $\mathrm{P}_{3}$ and simple equation to apply. A thermal solar power station consists of a production of solar system of heat which feeds from the turbines in a thermal cycle of electricity production.

\section{B. Wind energy}

The power contained in the form of kinetic energy, $\mathrm{P}(\mathrm{W})$, the wind is expressed by:

$$
P=\frac{1}{2} \cdot \rho \cdot A \cdot v^{3}
$$

with:

A is the area traversed by the wind ( $\mathrm{m} 2) ; \rho$ is the density of air $(=1.225 \mathrm{~kg} / \mathrm{m} 3)$ and $\mathrm{v}$ is the wind speed $(\mathrm{m} / \mathrm{s})$.

The wind generator can recover some of this wind power and represents the power produced by wind generator:

$$
P_{e l}=\frac{1}{2} \cdot \rho \cdot C_{e} A \cdot v^{3} \cdot 10^{-3}
$$

$\mathrm{C}_{\mathrm{e}}$ is the efficiency factor, which depends on the wind speed and the system architecture [4].

\section{Economic Dispatch}

Optimization of cost of generation has been formulated based on classical OPF with line flow constraints. The detailed problem is given as follows [5].

$$
F=\operatorname{Min} \sum_{i=1}^{N G} f\left(P_{G i}\right)
$$

The cost function $f\left(P_{G i}\right)$ is usually expressed as a quadratic polynomial [6].

$$
f\left(P_{G i}\right)=a_{i} P_{G i}^{2}+b_{i} P_{G i}+c_{i}
$$

The minimization the daily total cost of active power generation may be expressed by:

$$
F=\operatorname{Min} \sum_{i=1}^{24} \sum_{i=1}^{N G} f\left(P_{G i}\right)
$$

The minimum value of the above objective function has to be found out by satisfying the following constraints [7]:

$$
\sum_{i=1}^{N G} P_{G i}+\sum_{k=1}^{N G k} P_{G R k}-P_{D}-P_{L}=0
$$

The generation capacity of each generator has some limits and it can be expressed as [8]:

$$
P_{G i}^{\min } \leq P_{G i} \leq P_{G i}^{\max }
$$

In minimizing the cost, the equality constraint (power balance) and inequality constraint (power limits) should be
satisfied.The transmission loss can be represented by the Bcoefficient method as

$$
P_{L}=\sum_{i} \sum_{j} P_{G i} B_{i j} P_{G j}
$$

Where $B_{i j}$ is the transmission loss coefficient, $P_{i}, P_{j}$ are the power generation of ith and jth units. The B-coefficients are found through the Z-bus calculation technique.

Where

$P_{G i}^{\min }, P_{G i}^{\max }:$ Lower and upper limit of active power generation at bus $\mathrm{i}$

$a_{i}, b_{i}, c_{i}$ the cost coefficients of the $\mathrm{i}$ th generator.

$P_{G i}$ :The power output of generator $\mathrm{i}$ in $\mathrm{MW}$;

$P_{D}$ : Active power load total

$P_{G i}:$ Active power generation at bus $\mathrm{i}$

$P_{G R k}$ : Active power renewable generation at bus $\mathrm{k}$

$P_{L}:$ Real losses

$N G$ : Number of thermal generators connected in the network.

$N G R$ : Number of renewable generator

\section{Minimization of pollutants emission}

The most important emissions considered in the power generation industry due to their effects on the environment are sulfur dioxide $\left(\mathrm{SO}_{2}\right)$ and nitrogen oxides $\left(\mathrm{NO}_{\mathrm{x}}\right)$ [9]. These emissions can be modeled through functions that associate emissions with power production for each unit $[10,11]$. One approach to represent $\mathrm{SO}_{2}$ and $\mathrm{NO}_{\mathrm{x}}$ emissions is to use a combination of polynomial and exponential terms [12]:

$$
E C(P g)=\sum\left(\alpha_{i} P_{g i}^{2}+\beta_{i} P_{g i}+\gamma_{i}\right)+\varepsilon_{i} \exp \left(\lambda_{i} P_{g i}\right)
$$

$$
P_{L}=0
$$

where

$\alpha_{i}, \beta_{i}, \gamma_{i}, \varepsilon_{i}$ and $\lambda_{i}$ are coefficients of the ith generator emission characteristics..

The bi-objective combined economic emission dispatch problem is converted into single optimization problem by introducing price penalty factor $\mathrm{h}$ as follows.

\section{Minimise $\mathrm{F}=\mathrm{FC}+\mathrm{h} * \mathrm{EC}$}

Subjected to the power flow constraints of equations[13]. The price penalty factor $h$ blends the emission with fuel cost and $\mathrm{F}$ is the total operating cost in $\$ / \mathrm{h}$. The price penalty factor $\mathrm{hi}$ is the ratio between the maximum fuel cost and maximum emssion of corresponding generator.

$$
h_{i}=\frac{F C\left(P_{g i}^{\max }\right)}{E C\left(P_{g i}^{\max }\right)}
$$


The following steps are used to find the price penalty factor for a particular load demand

1. Find the ratio between maximum fuel cost and maximum emission of each generator.

2. Arrange the values of price penalty factor in ascending order.

3. Add the maximum capacity of each unit $P_{g i}^{\max }$ one at a time, starting from the Smallest hi unit until $\sum P_{g i}^{\max } \geq P_{d}$

4. At this stage, hi associated with the last unit in the process is the price penalty factor $h$ for the given load.

The above procedure gives the approximate value of price penalty factor computation for the corresponding load demand. Hence a modified price penalty factor $(\mathrm{hm})$ is introduced in this work to give the exact value for the particular load demand. The first two steps of $h$ computation remain the same for the calculation of modified price penalty factor. Then it is calculated by interpolating the values of hi corresponding to their load demand values.

\section{FIREFLY ALGORITHM (FFA)}

Fireflies (lightning bugs) use their bioluminescence to attract mates or prey. They live in moist places under debris on the ground, others beneath bark and decaying vegetation.

Firefly Algorithm (FFA) was developed by Xin-She Yang at Cambridge University in 2007. It uses the following three idealized rules: 1) All fireflies are unisex so that a firefly will be attracted to other fireflies regardless of their sex. 2) Attractiveness is proportional to their brightness; thus for any two flashing fireflies the less brighter will move towards the brighter one. The attractiveness is proportional to the brightness and they both decrease as their distance increases. If there is no brighter firefly than a particular one it will move randomly. 3) The brightness of a firefly is affected or determined by the landscape of the objective function. On the first rule, each firefly attracts all the other fireflies with weaker flashes [14]. All fireflies are unisex so that one firefly will be attracted to other fireflies regardless of their sex. Secondly, attractiveness is proportional to their brightness which is reversely proportional to their distances. For any two flashing fireflies, the less bright one will move towards the brighter one. The attractiveness is proportional to the brightness and they both decrease as their distance increases. If there is no brighter one than a particular firefly, it will move randomly. Finally, no firefly can attract the brightest firefly and it moves randomly. The brightness of a firefly is affected or determined by the landscape of the objective function. For a maximization problem the brightness can simply be proportional to the value of the objective function. Other forms of brightness can be defined in a similar way to the fitness function in genetic algorithms based on these three rules.

\section{1) Attractiveness}

In the firefly algorithm there are two important issues: the variation of light intensity and the formulation of the attractiveness. For simplicity, we can always assume that the attractiveness of a firefly is determined by its brightness which in turn is associated with the encoded objective function [15]. In the simplest case for maximum optimization problems, the brightness I of a firefly at a particular location $x$ can be chosen as $I(x)$ corresponding to $f(x)$. However, the attractiveness $\beta$ is relative; it should be seen in the eyes of the beholder or judged by the other fireflies [16]. Thus, it will vary with the distance $r_{i j}$ between firefly $i$ and firefly $j$. In addition, light intensity decreases with the distance from its source and light is also absorbed in the media so we should allow the attractiveness to vary with the degree of absorption. In the simplest form, the light intensity $\mathrm{I}(\mathrm{r})$ varies according to the inverse square law $I(r)=I_{s} / r^{2}$ where $I_{s}$ is the intensity at the source. For a given medium with a fixed light absorption coefficient, the light intensity $I$ varies with the distance r [17].

That is $I=I_{0} e^{-\gamma r}$, where $\mathrm{I}_{0}$ is the original light intensity. In order to avoid the singularity at

$\mathrm{r}=0$ in the expression $I(r)=I_{s} / r^{2}$ the combined effect of both the inverse square law and absorption can be approximated using the following Gaussian form:

$$
I(r)=I_{0} e^{-r^{2}}
$$

Sometimes we may need a function which decreases monotonically at a slower rate. In this case we can use the following approximation:

$$
I(r)=\frac{1}{1+e r^{2}} I_{0} e^{-r^{2}}
$$

At a shorter distance, the above two forms are essentially the same. This is because the series expansions about $r=0$ have the form:

$$
e^{-\gamma^{2}} \approx 1-\gamma^{2}+. ., \frac{1}{1+\gamma^{2}} \approx 1-\psi^{2}+. .
$$

and are equivalent to each other up to the order of $0\left(\mathrm{r}^{3}\right)$.

Since a firefly's attractiveness is proportional to the light intensity seen by adjacent fireflies, we can now define the attractiveness $\beta$ of a firefly by:

$$
\beta(r)=\beta_{0} e^{-r^{2}}
$$

where $\beta_{0}$ is the attractiveness at $\mathrm{r}=0$. As it is often faster to calculate $1 /\left(1+r^{2}\right)$ than an exponential function, the above expression, if necessary, can conveniently be replaced by $\beta=\frac{\beta_{0}}{1+e r^{2}}$. Equation (9) defines a characteristic distance 
$\Gamma=\frac{1}{\sqrt{\gamma}}$ over which the attractiveness changes significantly from $\beta_{0}$ to $\beta_{0} e^{-1}$.

In the implementation, the actual form of attractiveness function $\beta(r)$ can be any monotonically form:

decreasing function such as the following generalized

$$
\beta(r)=\beta_{0} e^{-\gamma^{m}} \text { with } m \geq 1
$$

For a fixed $\gamma$, the characteristic length becomes $\Gamma=\gamma^{-1 / m} \rightarrow 1$ as $m \rightarrow \infty$.

Conversely, for a given length scale $\Gamma$ in an optimization problem, the parameter $\gamma$

can be used as a typical initial value. That is $\gamma=\frac{1}{\Gamma^{m}}$.

2)

\section{Distance and Movement}

The distance between any two fireflies $i$ and $j$ at $x_{i}$ and $x_{j}$ is the Cartesian distance given by [18] as follows:

$$
r_{i j}=\left|x_{i}-x_{j}\right|=\sqrt{\sum_{k}^{d}\left(x_{i, k}-x_{j, k}\right)^{2}}
$$

Where $x_{i k}$ is the $k$-th component of the spatial coordinate $x_{i}$ of $i$-th firefly as shown in fig.2 the movement of a firefly $i$ is attracted to another more attractive firefly $j$ is determined by

$$
x_{i+1}=x_{i}+\beta_{0} e^{-\lambda x_{i j}^{2}}\left(x_{j}-x_{i}\right)+\alpha\left(\operatorname{rand}-\frac{1}{2}\right)
$$

Where the first term is the current position of a firefly, the second term is used for considering a firefly's attractiveness to light intensity seen by adjacent fireflies and the third term is used for the random movement of a firefly in case there are not any brighter ones. The coefficient $\alpha$ is a randomization parameter determined by the problem of interest, while rand is a random number generator uniformly distributed in the space $[0,1]$. As we will see in this implementation of the algorithm, we will use $\beta_{0}=0.1, \alpha \in[0,1]$ and the attractiveness or absorption coefficient $\gamma=1.0$ which guarantees a quick convergence of the algorithm to the optimal solution (see figure 1).

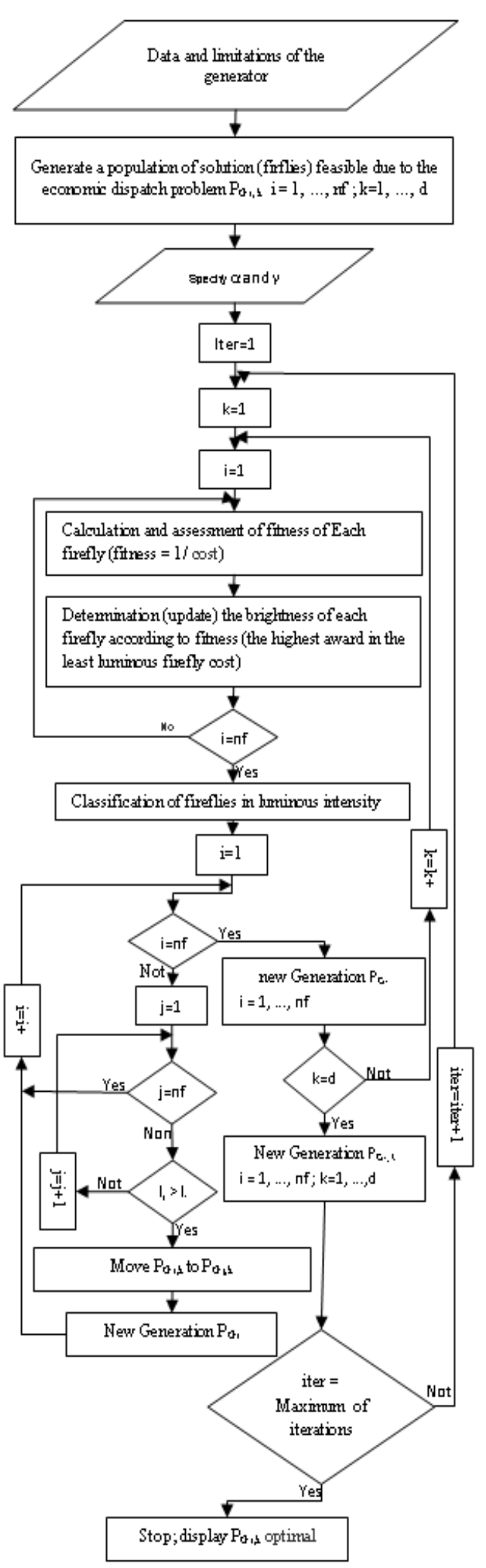

Fig. 1. Flow chart for EPD using Ferefly algorithm. 


\section{SIMULATION RESULTS}

The new firefly algorithm (FFA) was coded in the MATLAB environment. The test was performed on the Algerian 59-bus system. This network consists of 59 buses, 10 generators, 36 loads of $684.10 \mathrm{MW}$ and 83 branches. Table 2 shows the technical parameters of the 10 generators. These parameters were determined by curve fitting techniques based on real test data. with $\mathrm{PL}=19.6490 \mathrm{MW}$. To demonstrate the effectiveness of the proposed technique, two different cases have been considered, as follows:

Case1: calculate the total cost and emission to Algerian electrical network without renewable energy.

Case 2: Minimize the total cost function and the emission, with renewable energy.

It is noticed that the proposed method (FFA) gives reduction in fuel cost and the emission in case 1 without renewable energy (Table III). The convergence profiles of the best solution for the fuel cost, the emission, the fuel cost and the emission are shown in Fig. 2, 3,4 and 5, respectively. from Table 4 taking into account the renewable-energy ( case 2), we can notice that the optimization has been greatly improved (see figures 6,7,8 and 9). It is noticed also from these figures that the convergence of the proposed approach (FFA) is promising, we got the results after only 50 iterations.

TABLE I. POWER GENERATION LMITS COST COEFICIENT DATA OF COMPARISON OF GENERATING UNITS OF 10-UNIT SYSTEM.

\begin{tabular}{|l|c|c|c|c|c|}
\hline $\begin{array}{c}\text { Bus } \\
\text { No }\end{array}$ & \multicolumn{2}{|c|}{$\begin{array}{c}\text { Power limit } \\
\text { (MW) }\end{array}$} & \multicolumn{3}{c|}{ Cost Coefficients } \\
\hline & $\begin{array}{c}p_{G i}^{\min } \\
(\mathrm{Mw})\end{array}$ & $\begin{array}{c}p_{G i}^{\max } \\
(\mathrm{MW})\end{array}$ & $a_{i}$ & $b_{i}$ & $c_{i}$ \\
\hline 1 & 8 & 72 & 0.0085 & 1.50 & 0 \\
\hline 2 & 10 & 70 & 0.0170 & 2.50 & 0 \\
\hline 3 & 30 & 510 & 0.0085 & 1.50 & 0 \\
\hline 4 & 20 & 400 & 0.0085 & 1.50 & 0 \\
\hline 5 & 15 & 150 & 0.0170 & 2.50 & 0 \\
\hline 6 & 10 & 100 & 0.0170 & 2.50 & 0 \\
\hline 7 & 10 & 100 & 0.0030 & 2.00 & 0 \\
\hline 8 & 15 & 140 & 0.0030 & 2.00 & 0 \\
\hline 9 & 18 & 175 & 0.0030 & 2.00 & 0 \\
\hline 10 & 15 & 140 & 0.0030 & 2.00 & 0 \\
\hline 11 & 0 & 30 & $/$ & $/$ & $/$ \\
\hline 12 & 0 & 10 & $/$ & $/$ & $/$ \\
\hline
\end{tabular}

TABLE II. EMISSION CO-EFICIENT DATA OF GENERATING UNITS OF 10-UNIT SYSTEM.

\begin{tabular}{|l|l|l|l|l|l|}
\hline $\begin{array}{l}\text { Bus } \\
\text { No }\end{array}$ & \multicolumn{5}{|c|}{ Emission Coefficients } \\
\hline & $\alpha_{i}$ & $\beta_{i}$ & $\gamma_{i}$ & $\gamma_{i}$ & $\lambda_{i}$ \\
\hline 1 & 4.091 & -5.554 & 6.490 & $2.00 \mathrm{e}-04$ & 2.857 \\
\hline
\end{tabular}

\begin{tabular}{|l|l|l|l|l|l|}
\hline 2 & 2.543 & -6.047 & 5.638 & $5.00 \mathrm{e}-04$ & 3.333 \\
\hline 3 & 4.258 & -5.094 & 4.586 & $1.00 \mathrm{e}-06$ & 8.000 \\
\hline 4 & 5.326 & -3.550 & 3.380 & $2.00 \mathrm{e}-03$ & 2.000 \\
\hline 5 & 4.258 & -5.094 & 4.586 & $1.00 \mathrm{e}-06$ & 8.000 \\
\hline 6 & 6.131 & -5.555 & 5.151 & $1.00 \mathrm{e}-05$ & 6.667 \\
\hline 7 & 4.091 & -5.554 & 6.490 & $2.00 \mathrm{e}-04$ & 2.857 \\
\hline 8 & 2.543 & -6.047 & 5.638 & $5.00 \mathrm{e}-04$ & 3.333 \\
\hline 9 & 4.258 & -5.094 & 4.586 & $1.00 \mathrm{e}-06$ & 8.000 \\
\hline 10 & 5.326 & -3.550 & 3.380 & $2.00 \mathrm{e}-03$ & 2.000 \\
\hline
\end{tabular}

TABLE III. BEST COMPROMISE OUTPUT FOR 10 GENERATOR SYSTEM (CASE 1)

\begin{tabular}{|c|c|c|c|}
\hline & $\begin{array}{c}\text { minimum } \\
\text { cost }\end{array}$ & $\begin{array}{c}\text { minimum } \\
\text { emission }\end{array}$ & $\begin{array}{c}\text { minimum } \\
\text { cost and } \\
\text { emission }\end{array}$ \\
\hline $\mathrm{P}_{\mathrm{G} 1(\mathrm{MW})}$ & 27.651275 & 34.905620 & 63.912720 \\
\hline $\mathrm{P}_{\mathrm{G} 2(\mathrm{MW})}$ & 10.236654 & 44.582265 & 28.630876 \\
\hline $\mathrm{P}_{\mathrm{G} 3(\mathrm{MW})}$ & 98.577976 & 78.694207 & 150.449182 \\
\hline $\mathrm{P}_{\mathrm{G} 4(\mathrm{MW})}$ & 164.521511 & $\begin{array}{c}134.06968 \\
3\end{array}$ & 137.938443 \\
\hline $\mathrm{P}_{\mathrm{G} 5(\mathrm{MW})}$ & 25.823325 & 68.474983 & 19.607090 \\
\hline $\mathrm{P}_{\mathrm{G} 6(\mathrm{MW})}$ & 10.010182 & 32.812131 & 17.749961 \\
\hline $\mathrm{P}_{\mathrm{G} 7(\mathrm{MW})}$ & 67.760025 & 51.259948 & 78.499539 \\
\hline $\mathrm{P}_{\mathrm{G} 8(\mathrm{MW})}$ & 129.423035 & $\begin{array}{c}105.64282 \\
9\end{array}$ & 112.362983 \\
\hline $\mathrm{P}_{\mathrm{G} 9(\mathrm{MW})}$ & 83.473542 & $\begin{array}{c}119.68095 \\
7\end{array}$ & 23.007701 \\
\hline $\mathrm{P}_{\mathrm{G} 10(\mathrm{MW})}$ & 85.693984 & 33.202681 & 71.361280 \\
\hline $\mathrm{P}_{\mathrm{GR} 1(\mathrm{MW})}$ & 0.00 & 0.00 & 0.00 \\
\hline $\mathrm{P}_{\mathrm{GR} 2(\mathrm{MW})}$ & 0.00 & 0.00 & 0.00 \\
\hline $\mathrm{P}_{\mathrm{D}(\mathrm{MW})}$ & 684.10 & 684.10 & 684.10 \\
\hline $\mathrm{P}_{\mathrm{L}(\mathrm{MW})}$ & 19.1715 & 19.3253 & 19.4198 \\
\hline $\mathrm{Cost}_{1}(\$ / \mathrm{h})$ & 1723.830137 & 1781.1538 & 1744.32416 \\
\hline $\begin{array}{c}\text { Emission } \\
(\mathrm{ton} / \mathrm{h})\end{array}$ & 0.454346 & 0.381361 & 0.401380 \\
\hline $\mathrm{T}_{(\mathrm{s})}$ & 0.82813 & 0.78125 & 0.81250 \\
\hline
\end{tabular}

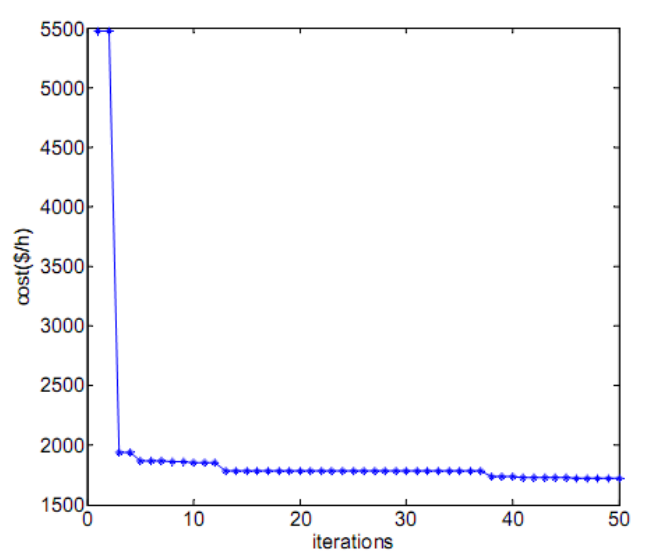

Fig. 2. Convergence characteristic for fuel cost minimization for case 1 (minimum cost) 


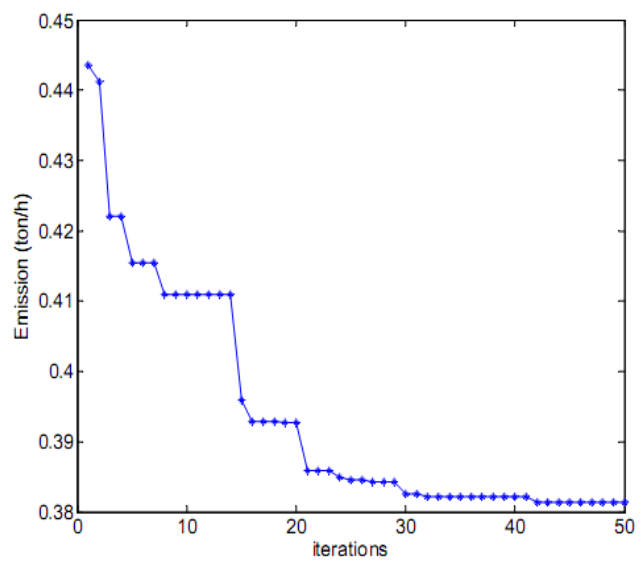

Fig. 3. Convergence characteristic for emission minimization for case 1 (minimum emission)

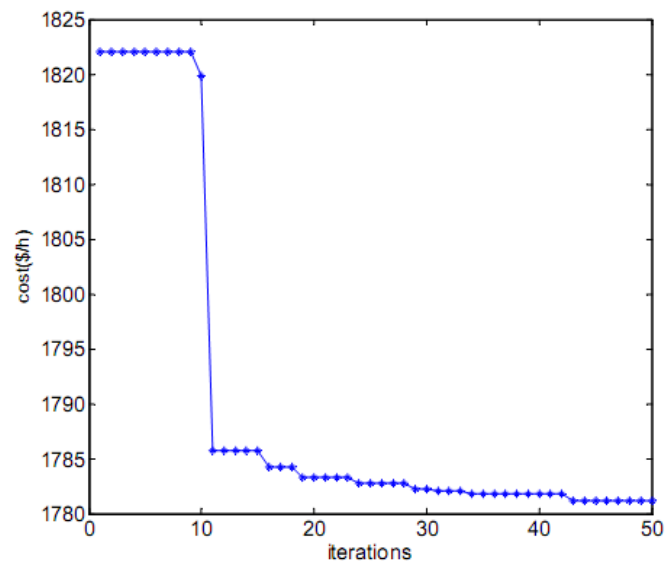

Fig. 4. Convergence characteristic for fuel cost minimization for case 1 (minimum cost and emission)

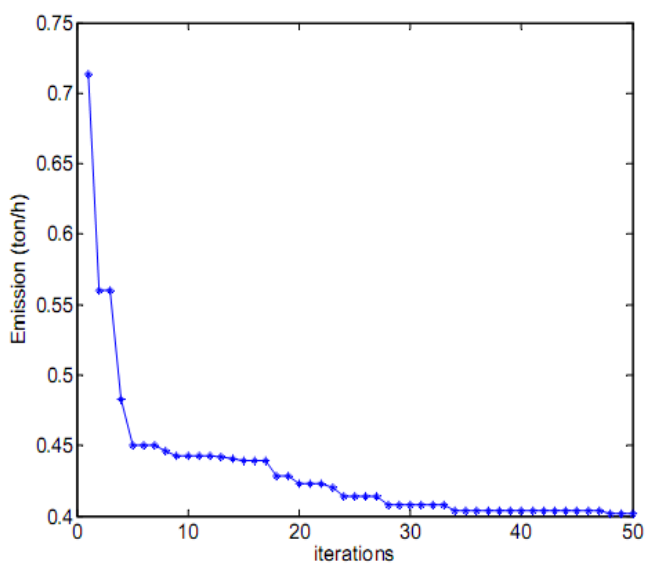

Fig. 5. Convergence characteristic for emission minimization for case 1 (minimum cost and emission)
TABLE IV. BEST COMPROMISE OUTPUT FOR 10 GENERATOR (CASE 2)

\begin{tabular}{|c|c|c|c|}
\hline & minimum cost & $\begin{array}{c}\text { minimum } \\
\text { emission }\end{array}$ & $\begin{array}{c}\text { minimum } \\
\text { cost and } \\
\text { emission }\end{array}$ \\
\hline $\mathrm{P}_{\mathrm{G} 1(\mathrm{MW})}$ & 35.126728 & 26.927115 & 44.607584 \\
\hline $\mathrm{P}_{\mathrm{G} 2(\mathrm{MW})}$ & 40.630506 & 51.606233 & 41.527364 \\
\hline $\mathrm{P}_{\mathrm{G} 3(\mathrm{MW})}$ & 112.232408 & 81.774188 & 58.197489 \\
\hline $\mathrm{P}_{\mathrm{G} 4(\mathrm{MW})}$ & 109.720341 & 54.829520 & $\begin{array}{c}116.90814 \\
6\end{array}$ \\
\hline $\mathrm{P}_{\mathrm{G} 5(\mathrm{MW})}$ & 23.952401 & 35.894921 & 45.133375 \\
\hline $\mathrm{P}_{\mathrm{G} 6(\mathrm{MW})}$ & 24.829224 & 67.783741 & 17.569297 \\
\hline $\mathrm{P}_{\mathrm{G} 7(\mathrm{MW})}$ & 53.465187 & 95.082396 & 15.254955 \\
\hline $\mathrm{P}_{\mathrm{G} 8(\mathrm{MW})}$ & 122.255830 & 92.478793 & $\begin{array}{c}128.30054 \\
6\end{array}$ \\
\hline $\mathrm{P}_{\mathrm{G} 9(\mathrm{MW})}$ & 46.207456 & 84.254893 & $\begin{array}{c}149.53460 \\
7\end{array}$ \\
\hline $\mathrm{P}_{\mathrm{G} 10(\mathrm{MW})}$ & 94.906182 & 72.301011 & 45.194946 \\
\hline $\mathrm{P}_{\mathrm{GR} 1(\mathrm{MW})}$ & 30.000000 & 30.000000 & 30.000000 \\
\hline $\mathrm{P}_{\mathrm{GR} 2(\mathrm{MW})}$ & 10.000000 & 10.000000 & 10.000000 \\
\hline $\mathrm{P}_{\mathrm{D}(\mathrm{MW})}$ & 684 & 684 & 684 \\
\hline $\mathrm{P}_{\mathrm{L}(\mathrm{MW})}$ & 19.3263 & 10.2572 & 18.2283 \\
\hline $\mathrm{Cost}_{(\$ / \mathrm{h})}$ & 1644.965062 & 1680.60856 & 1658.9628 \\
8 & 65 \\
\hline $\begin{array}{c}\mathrm{E} \\
\text { (tonission } / \mathrm{h})\end{array}$ & 0.362192 & 0.290030 & 0.31325 \\
\hline $\mathrm{T}_{(\mathrm{s})}$ & 0.98438 & 1.024581 & 1.01563 \\
\hline
\end{tabular}

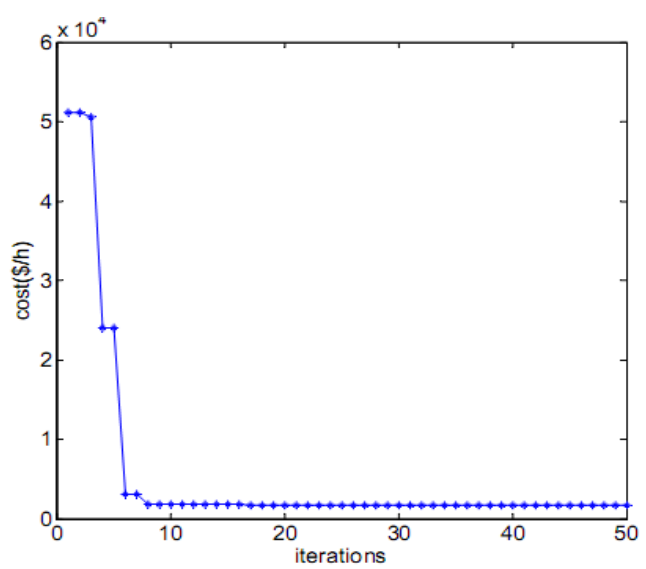

Fig. 6. Convergence characteristic for fuel cost minimization for case 2 (minimum cost) 


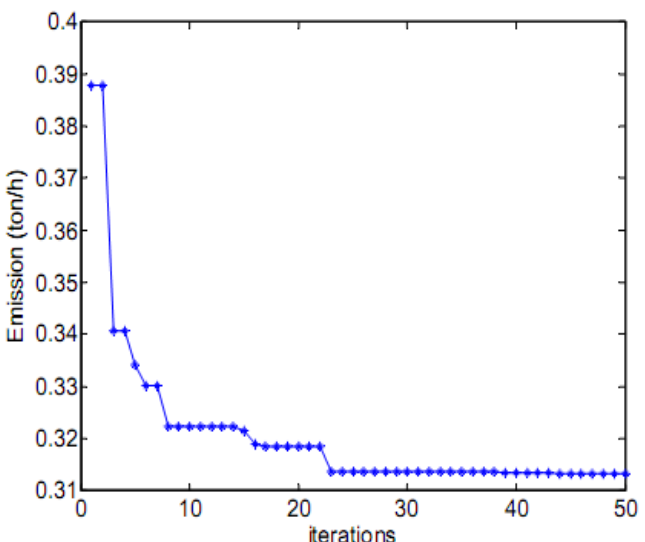

Fig. 7. Convergence characteristic for emission minimization for case 2 (minimum emission)

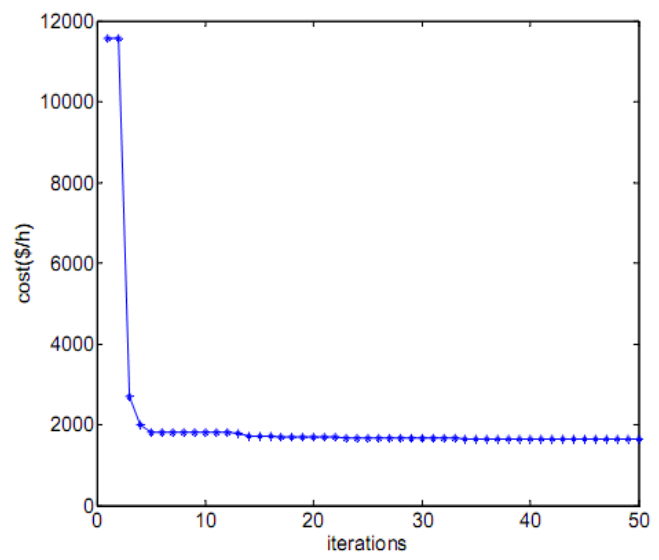

Fig. 8. Convergence characteristic for fuel cost minimization for case2 (minimum cost and emission)

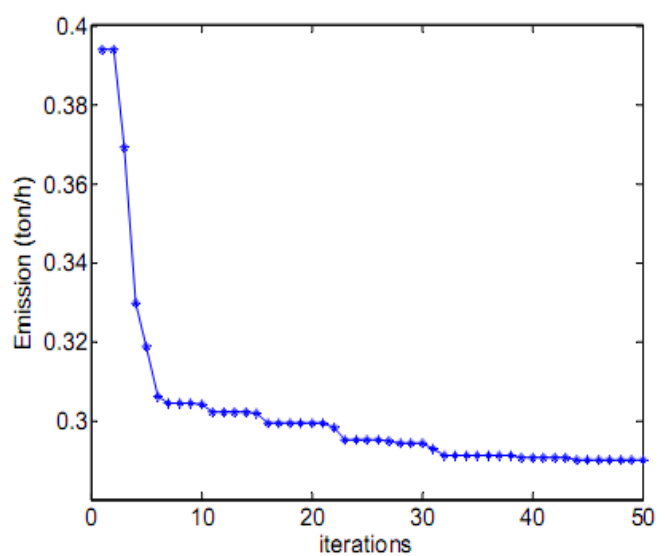

Fig. 9. Convergence characteristic for emission minimization for case2 (minimum cost and emission)

\section{CONCLUSION}

Most of the countries are investing in renewable energy technology to meet emission target and increase the share of power from renewable energy sources. our work strengthens the idea and gives a method for the integration of renewable energies in the classical system.

\section{REFERENCES}

[1] Muneer T, Asif M, Munawwar S. Sustainable production of solar electricity with particular reference to the Indian economy. Renewable and Sustainable Energy Reviews 2005;9:444-73

[2] R. Saidur, M.R. Islam, N.A. Rahim, K.H. Solangi, A review on global wind energy policy, Renewable and Sustainable Energy Reviews 2010;14: 1744-1762

[3] Faisal A. Mohamed, Heikki N. Koivo., (2007), Online Management of Micro Grid with Battery Storage Using Multiobjective Optimization, POWERENG 2007, April 12-14,

[4] Nadine May. Eco-balance of a Solar Electricity Transmission from North Africa to Europe. Diploma Thesis, Faculty for Physics and Geological Sciences, Technical University of Braunschweig; 2005

[5] O. Alsac, J. Bright, M. Prais, and B. Stott, "Further developments in LPbased optimal power flow," IEEE Transactions on Power Systems, Vol. 5, 1990, pp. 697-711.

[6] J. Nanda, D. P. Kothari, and S. C. Srivatava, "New optimal powerdispatch algorithm using Fletcher's quadratic programming method," in Proceedings of the IEE, Vol. 136, 1989, pp. 153-161.

[7] R. D. Zimmerman, C. E. Murillo-S_anchez, and R. J. Thomas, Matpower's extensible optimal power ow architecture," Power and Energy Society General Meeting, 2009 IEEE, July 26-30 2009, pp. 1-7.

[8] H. W. Dommel, "Optimal power dispatch," IEEE Transactions on Power Apparatus and Systems, Vol. PAS93, 1974, pp. 820-830.

[9] Basu M. Dynamic economic emission dispatch using nondominated sorting genetic algorithm- II. Electr Power Energy Syst 2008;30(2):1409.

[10] Jiang X, Zhou J, Wang H, Zhang Y. Dynamic environmental economic dispatch using multi-objective differential evolution algorithm with expanded double selection and adaptive random restart. Int J Electr Power Energy Syst 2013;49:399-407.

[11] Zhang R, Zhou J, Mo L, Ouyang S, Liao X. Economic environmental dispatch using an enhanced multi-objective cultural algorithm. Electr Power Syst Res 2013;99:18-29

[12] Basu M. Economic environmental dispatch using multi-objective differential evolution. Appl Soft Comput 2011;11(2):2845-53.

[13] Provas Kumar Roy, Sudipta Bhui, "Multi-objective quasi-oppositional teaching learning based optimization for economic emission load dispatch problem", Electrical Power and Energy Systems 53 (2013) 937-948.

[14] Fraga .H. (2008)., Firefly luminescence: A historical perspective and recent developments, Journal of Photochemical \& Photobiological Sciences, vol. 7, pp. $146-158$.

[15] Yang .X.S., (2009). Firefly algorithms for multimodal optimization, Stochastic Algorithms: Foundations and Applications Lecture Notes in Computer Sciences, vol. 5792, pp. 169-178.

[16] Yang .X. S., "Firefly algorithm, stochastic test functions and design optimisation, International Journal of Bio-Inspired Computation, vol. 2 n. 2, pp. $78-84,2010 .(13)$

[17] S. X. Yang, "Firefly Algorithm", Engineering Optimization. Hoboken, New Jersey: Wiley, 2010, pp. 221-230.

[18] Xin-She Yang, "Firefly Algorithm", Engineering Optimization:An Introduction with Metaheuristic Applications, pp 221-230, Wiley,2010.

\section{Creative Commons Attribution License 4.0 (Attribution 4.0 International, CC BY 4.0)}

This article is published under the terms of the Creative Commons Attribution License 4.0

https://creativecommons.org/licenses/by/4.0/deed.en US 